\title{
De rol van de accountant, nu en in de toekomst
}

\section{Deel 1}

\section{Prof. J.C.A. Gortemaker}

\section{Inleiding}

Intemationalal bezien dienen zich voor de accountancy en de accountant belangrijke mogelijkheden aan. Genoemd word op deze plaats de ontwikkeling van de accountancy in de zogenoemde emerging markets. Het is de verwachting dat in dal deel van de wereld de accountantskantoren zeer belangrijke investeringen zullen verrichten en deels al verrichten. Mensen en middelen zullen daarheen verplaatsi worden. Deze beweging wordt ingegeven door de keuzes die de cliënten van de accountantskantoren maken. Maar ook in de landen. waar de accountancy reeds een stuk geschiedenis achter de rug heeft. dienen zich nieuwe mogelijkheden aan. In deze bijdrage zullen onder meer nieuwe assurance services belicht worden. Ook wijzigingen in governance-structuren en gewijzigde opvaltingen terzake zullen een belangrijke invloed hebben op de rol van de accountant. Bij dit proces is het, gezien de internalionalisatie van de werkzaamheden, van belang dat zich op accounting-en auditing-gebied cen verdergaande harmonisatie afspeelt. In dit verband zijn de contacten tussen International Organisation of Securities Commissions (IOSCO). International Accounting Standards Committee (IASC) en International Auditing Practices Committee (IAPC) relevant.

Teneinde zicht te krijgen op de (toekomstige) rol van de openbaar accountant - bezien vanuit een internationalal perspectiel - is het van belang na te gaan welke factoren hierop van invloed zijn. In deze bijdrage zullen de ontwikkelingen als volgt aan de orde komen:

- Assurance services framework van het IAPC (IFAC);
- Europese ontwikkelingen. aan de hand van het Green Paper en het rapport van de European Contact Group.

Onder het hoofd evaluatie zullen een antal toekomstige ontwikkelingen worden samengevat, bezien naar de gezichtspunten: organisatie, producten en waarborgen.

\section{Assurance Services Framework}

Het International Auditing Practices Conmit tee (IAPC) van de International Federation of Accountants (IFAC) houdt zich al enige tijd bezig met het ontwerpen van cen assurance services framework. Deze activiteit is ingegeven door het feit dal. naast de controle van historische financiële gegevens, een toenemende behoefte bestaat an het toevoegen van zekerheid met betrekking tot onder meer: toekomstige informatie, internecontrolesystemen alsmede naleving wet- en regelgeving. Hoewel de discussie nog in volle gang is, volgen hiema enige denkrichtingen. De werkzaamheden van accountants kumnen onderscheiden worden naar assurance services en andere vormen van dienstverlening, walaronder de adviesfunctie. Assurance services zijn professionele diensten ten behoeve van degenen die beslissingen moeten nemen en die erop gericht zijn de geloofwaurdigheid/betrouwbararheid van informatie, een systeem of een proces te doen toenemen. Hiertoe dient een verantwoordelijke partij ten

Prof. J.C.A. Gortemaker RA is voorzitter beroepsgroep accountants bij Coopers \& Lybrand. Voorts is bij hoogleraar accountancy aan de Erasmus Universiteit Rotterdam en Nijenrode University Breukelen. Tevens is hij Lid International Auditing Practices Committee en Lid Auditing Working Party FEE. 
aanzien van de hiervoor genoemde objecten aanwezig te zijn en dienen criterial walaran getoelst kan worden voorhanden te zijn. De assurance services kunnen zich richten op historische en toekomstgerichte financiële informatie. niet-financiële operationele gegevens. wet- en regelgeving, interne-controlesystemen, corporate governance, statistische analyses, human resource-aingelegenheden, kwaliteitsstandaards en performance-indicatoren. Als werkitel voor degene die deze diensten verricht, is voorshands gekozen voor prolessional accountant. Een belangrijk element in het proces zijn de criteria. walarain getoetst moet worden. Hierbij valt te denken aan de international accounting standards. cen gezaghebbend internal control framework (bijvoorbeeld COSO), en in siluaties van hel naleven van wet-, regelgeving en contracten. kunnen deze criteria in de betreffende stukken zelf bestoten liggen. De wijze valn rapportering, en dit geldı met name voor de nieuw ontwikkelde werkzalimheden, is van groot belang. De mate van 'vermeerderde geloof watardigheid' die hieruit voortvloeit is onder meer afhankelijk van de alard van het object. de criteria en het bewijsmateriatal. $\mathrm{Bij}$ de gedachtewisseling omtrent het nieuwe framework dienen de leden van IAPC voortdurend alert te zijn niet in de bestiande denkkalders (box) van bijvoorbeeld het audit lranework te blijven. Dit geldt evenzo voor de gewenste vorm van rapportering, alhankelijk van zekcrheidsniveaus. Bij de discussie zoals deze thans plaatsvindt binnen IAPC blijkl. dal de concepten van risicoanalyse en materialiteit hun nut blijven bewijzen. Tevens komt hierbij naar voren dal de werkzaamheden zich veelal in een multidisciplinair samengesteld team zullen afspelen.

\section{Europese ont wikkelingen}

In januari 1996 publiceerde de Fédération des Experts Comptables Europécns het rapport The Role. Position and Liability of the Statutory Auditor in the European Union. Op dit rapport zal in dit artikel niet explicict worden ingegaan. Aandacht zal worden gegeven aan twee Europese rapporten die in de tweede helft van 1996 zijn verschenen:

- Green Paper, the role, the position and the liability of the statutory auditor within the European Union, van de zijde van de Europese Commissie;
- Responding to market expectations an action plan to reduce the expectition gap. opgesteld door de European Contact Group (achı grote internationale accountantskantoren).

Zoals het tijdstip van publicatie reeds doet vermoeden. tonen beide rapporten een samenhang. Laatstgenoemd rapport geefi deels een reaclie op onderwerpen die in het document van de Europese Commissie genoemd zijn. Allereerst zall het discussiestuk Green Paper alan de orde komen. Bij het opstellen van het rapport heefi de Europese Commissie gebruik gemalakt van een rescarchstudie van het MARC (Malastricht Accounting en Auditing Research Center) d.d. maarl 1996. De Commissie verwacht reacties op het Green Paper en inmiddels (december 1996) heeft ontrent de in het Green Paper genoemde onderwerpen een conferentie plaatsgevonden. Bij de bespreking van dit rapport zall het accent op de rol en de positie van de accountant liggen. Het rapport vangt aan met de constatering dat, als gevolg van een alantal belangrijke deconfitures, de rol en de onafhankelijkheid van de accountant wereld wijd voorwerp van discussie zijn.

Het benadrukt de betekenis van de wetlelijke controle gericht op de bescherming van het ilgemeen belang en de betrouwbarheid van linanciële informatie. Hoewel in de vierde, zevende en achtste Richtlijn bepalingen zijn opgenomen, ontbreekt het in Europa aan een gemeenschappelijke visie op de rol, positie en aansprakelijkheid van de accountant. Dit heeft volgens de Commissie een negatiove invloed op de kwaliteit van de controle en op de vrijheid van vestiging en hel verrichten van diensten. Tevens wordt in de inleiding van het Green Paper het belang onderkend van wereldwijde controlestandaarden. Internationale kapitaalmarkien zullen slechts jaarrekeningen accepteren voorzien van accountantsverklaningen. gebaseerd op deze standaarden. In dit verband zijn de International Standards on Auditing (ISA) van het IAPC relevant. De Europese Commissie onderzoek that steun voor deze grondslagen en bezint zich op de Europese invloed op de totstandkoming. Het hoofdstuk dal de rol van de accountant uiteenzet. vangl aan met een beschouwing over de verwachtingskloof. Redelijke verwachtingen van gebruikers van accountantsdiensten dienen gebaseerd te zijn op:

- wettelijke taken:

- effectieve vralag: stakeholders zijn bereid voor de dienst te betalen; 
- accountants die de dienst willen en kunnen verrichten.

De verwachtingen van de gebruikers worden hierna beknopt besproken:

- De juistheid van de juarrekening: niteengezet word dat het de taak van management is de jaarrekening op te stellen en dat de accountant verklaart dat, naar zijn oordeel. de jaarrekening een getrouw beeld geeft. Aangegeven wordt dat getrouw beeld (true and fair view) een andere inhoud heeft dan het door veel gebruikers verwachte begrip juistheid (accurate).

- Going concern-problematick: jaarrekeningen worden opgesteld op basis van continuïteit. Een aantal landen overweegt management expliciet te laten verklaren dat de onderneming in staat is haar activiteiten voort te zetten. Accountants hebben een signalerende taak richting management en toezichthouders met betrekking tot zaken die de continuïteit bedreigen. Gewezen wordt op het risico indien de accountant omtrent de continuïteitspositie mededelingen naar buiten brengt (selffullilling prophecy): anderzijds blijkt uit onderzoek verricht in het Verenigd Koninkrijk dat overlevingskansen van ondernemingen hierdoor niel significant beïnvloed worden. Verschillende rapporten op het gebied van corporate governance (Cadbury, Vienot) bevelen aan. dat het management expliciet zijn zienswijze hierop kenbaar maakt. Deze opvatting wordt door de Commissie gedeeld.

- Fraude en het naleven ran wettelijke verplichingen: het maatschappelijk verkeer verwacht dat accountants fraude ontdekken. Accountants hebben tot onlangs geen accent op deze rol gelegd. Als gevolg van overheidsbemoeienis in een alantal Europese landen is deze situatie gewijzigd. Thans tekent zich het volgende beeld af: management heeft terzake een primaire verantwoordelijkheid. Zij dient zorg te dragen voor een adequaat systeem van interne controle. Accountants moeten hun controleplan zo opstellen, dat een redelijke zekerheid bestaal dat materiële fraude, alsmede inbreuken op wet- en regelgeving. worden ontdekt. Aanwijzingen voor fraude, alsmede inbreuken op wel- en regelgeving dienen gemeld te worden aun het management en of de toezichthouder en in een aantal gevalten aan de overheid. Het komt de Commissie redelijk voor dat in de accountantsverklaring melding wordt gemaakı van een effectief systeem van interne controle gericht op fraudepreventie en naleving van wet-en regelgeving.

- Houding onderneming met betrekking tot milieu- en sociale aspecten: het rapport werpt de vraiag op in hoeverre hier een tak voor accountants ligt of voor andere deskundigen. Er wordt evenwel op gewezen dat de verantwoordelijkheid van de accountants op het gebied van milieu- en sociale aspecten kan toenemen.

Ter afsluiting van het hoofdstuk omirent de rol van de accountant wordt alundacht besteed ain de accountantsverklaring. Gepleit wordt voor uniformering, een nadere uiteenzetting van werkzaamheden en vermelding van naleving van wet-en regelgeving. De betreffende ISA is ook hier weer van belang. De Commissie maakt zich in dit verband zorgen om het ontbreken van een wettelijk kader.

Nadat hiervoor de rol van de accountant uiteengezet is. wordt thans aandacht geschonken aan diens positie. Het hoofdstuk in het Green Paper. dat de positie van de accountant bespreekl. vangt aan met de constatering dat, ondanks het effect dal uitgaat van de Achtste Richtlijn, nog steeds geen sprake is van een gelijkwaardig niveau van opleiding in Europa. Universiteiten worden opgeroepen mede hierin een rol te spelen. Voorts wordt geconstateerd, dat de invloed van informatietechnologie een belangrijke invloed kan hebben op de accountantsfunctie. Nieuwe permanente - financiële informatiestromen ontstatan en de behoefte aan een oordeel bij deze informatie en de anwezige informatiesystemen dient zich alan.

Een kernpunt in het document vormt de onafhankelijkheid (of mind and in appearance). Een aantal bedreigingen worden genoemd: opinion shopping, second opinions, wisseling accountant. commercieel optreden accountants, offerteprocedures, offreren onder kostprijs, mede in relatie tot adviesfees, alsmede de combinatie controle- en advieswerkzaamheden. Ofschoon erkend wordt dat de combinatie controle en advies ook voordelen in zich draagt, worden maatregelen voorgesteld. Deze liggen deels in lijn met de aanbevelingen genoend in mijn oratie Panta Rhei (april 1991). De adviesdiensten moeten in overeensiem- 
ming zijn met het professionele beeld van de accountant en mogen diens objectiviteit niet aantasten. Ook aan publicatie van de controle- en adviesfees wordt gedacht. Bepaalde diensten zouden niet geleverd mogen worden. Voorgesteld wordt een systeem van partnerrotatie in te voeren. In het kader van corporate governance worden een aantal denkrichtingen aangegeven. Geconstateerd wordt dat de invloed van management op de accountant (te) groot is. Een aspect dat in dit verband genoemd wordt is de invloed van manage ment op de hoogte van de fees. Lagere fees betekenen dat de accountant minder tijd aan de controle kan besteden en minder goed in de gelegenheid is aandacht te schenken aan de beoordeling van het interne controlesysteem. Gepleit wordt onder meer bij de benoeming van de accountant audit committees een belangrijke rol te laten spelen. Voorts wordt aandacht gevraagd voor de instelling van een interne accountantsdienst. Ook wordt gedacht aan een vaste benoemingsperiode voor de accountant. Aan het einde van het hoofdstuk wordt gewezen op het belang van het systeem van kwaliteitszorg, alsmede het toezicht op de naleving hiervan. In dit verband wordt verwezen naar de ISA's. Gewezen wordt op een Europese invloed bij hun totstandkoming. Wederom wordt aandacht gevraagd voor wettelijke inkadering.

Thans komt het tweede onder het hoofd Europese ontwikkelingen genoemde rapport aan de orde.

Responding to market expectations geeft deels in samenhang met het in het Green Paper gestelde - de zienswijze van acht grote internationale accountantskantoren weer met betrekking tot de rol en de positie van de accountant in Europa. Een belangrijk onderdeel vormt de gedragscode voor het accountantsberoep. Een beroep dat uitgeoefend wordt vanuit multidisciplinair samengestelde kantoren. Deze veelal grote samenwerkingsverbanden zijn een realiteit en argumenten worden aangevoerd, die pleiten voor de multidisciplinaire samenwerking. Ook in dit document worden - evenals in het Green Paper - evenwel grenzen gesteld aan de uitbreiding van het dienstenpakket. De adviesdiensten moeten naar aard en kwaliteit in overeenstemming zijn met het professionele beeld van de accountant en mogen de objectiviteit met betrekking tot een cliëntrelatie niet aantasten. Binnen deze meerdienstenorganisaties vormt accountantscontrole een speciale activiteit, vanwege de publieke functie. Het is mede hierom van belang dat het management veel aandacht aan deze activiteit besteedt.

Teneinde de objectiviteit van de accountant te waarborgen, zijn in een gedragscode een aantal beginselen opgenomen:

- Sommige financiële, persoonlijke en zakelijke bindingen tussen accountant en cliënt moeten vermeden worden. Aspecten van financiële en relationele onathankelijkheid worden hierin onderkend.

- Bij het verlenen van adviesdiensten aan controlecliënten dient hetgeen hiervoor terzake is opgemerkt in acht te worden genomen. Bepaalde activiteiten worden onder omstandigheden uitgesloten.

- Voor wat de fees betreft, wordt een bepaalde gedragswijze aanbevolen. Contingent fees worden afgewezen. Onder dit hoofd komt ook het gevoelige punt van de omvang van de adviesdiensten aan de orde. Teneinde aan de gesignaleerde problematiek tegemoet te komen wordt overwogen de omvang van adviesdiensten een selectiecriterium te doen zijn bij onafhankelijke kwaliteitsreviews (peer reviews). Met andere woorden indien veel adviesdiensten worden verricht, neemt de kans betrokken te worden in het review toe. Voorts ligt voor wat betreft de omvang van de adviesdiensten er een taak voor de raad van commissarissen of audit committees.

- Ter waarborging van een juiste prijsstelling wordt gesteld, dat hiertoe binnen het kantoor consultatie- en reviewprocedures aanwezig dienen te zijn. Indien de hoogte van de fees wezenlijk afwijkt van die van de vorige accountant, zou dit wederom een selectiecriterium kunnen zijn voor een onafhankelijk kwaliteitsreview.

- Indien de accountant met zijn cliënt in een proces geraakt (of dreiging) dient de controlerelatie beëindigd te worden.

- Gewaarschuwd wordt voor risico's verbonden aan het afgeven van second opinions. Consultatieprocedures binnen het kantoor en overleg met de collega zijn van belang.

- Ten slotte worden nog enige waarborgen met betrekking tot het handhaven van de objectiviteit genoemd. Als eerste de verplichte rotatie van partners (bijvoorbeeld na zeven jaar) op bepaalde opdrachten. Voorts - eveneens voor 
bepaalde opdrachten - het introduceren van een tweede (review) partner. Onafhankelijke kwaliteitsreviews moeten - naast de reviews die de kantoren zelf uitvoeren - waken voor een juiste naleving van de controlestandaarden en de overige procedures. Binnen het kantoor moet de bewaking van de objectiviteit centraal staan. In dit verband is de slotzin van het hoofdstuk van belang: A firm of auditors must be controlled both as to voting rights and membership of its administrative or management bodies by individuals who are qualified as auditors.

In het rapport wordt geconcludeerd, dat de accountant duidelijk een stap naar voren moet doen als het gaat om zaken als toekomstgerichte informatie, going concern-problematiek en het ontdekken en rapporteren van fraude en onregelmatigheden. Een rolbeschrijving wordt gevraagd in het totale proces van corporate governance. Gepleit wordt voor verdere harmonisatie op het gebied van accounting (IASC) en auditing (IFAC, IAPC).

Met betrekking tot de accountantsverklaring wordt opgemerkt dat deze uitbreiding behoeft. Ook een uitbreiding naar rapportering omtrent kwartaal- en halfjaarcijfers (review) wordt genoemd. Management moet mededeling doen omtrent de going concern-problematiek en het systeem van interne controle. De accountant kan dan rapporteren dat deze mededelingen juist zijn. Voorts wordt nog aandacht gevraagd voor beperking van de aansprakelijkheid van de accountant en controles binnen concernverbanden. De meeste hiervoor genoemde onderwerpen zijn reeds aan de orde geweest bij de bespreking van het zogenoemde Green Paper.

\section{Evaluatie}

Thans zullen een aantal toekomstige ontwikkelingen worden samengevat die de rol van de accountant nu en in de toekomst mede zullen bepalen. De evaluatie zal langs drie lijnen (organisatie, producten en waarborgen) plaatsvinden en is mede gebaseerd op bovengenoemde studies, alsmede op eigen betrokkenheid bij internationale regelgeving binnen (IFAC, IAPC) en bij (inter)nationale ontwikkelingen binnen Coopers \& Lybrand.

\section{Organisatie}

Het accountantsberoep zal in belangrijke mate worden uitgeoefend in grote internationaal opererende meerdienstenorganisaties. De internationale samenwerking binnen deze organisaties zal verder worden versterkt. Vergaande integratieprocessen binnen de big six tekenen zich reeds af. Deze organisaties leveren, naast de accountantscontrole, tevens adviesdiensten. Er zijn meerdere argumenten te noemen voor de combinatie van diensten. De cliëntorganisatie vraagt om deze diensten, waarbij het overigens geen vanzelfsprekendheid is dat de adviesdiensten geleverd worden door dezelfde organisatie die de accountantscontrole verricht. De controleopdrachten zijn veelal dermate complex, dat teams multidisciplinair moeten zijn samengesteld. Voorts bieden de meerdienstenorganisaties goede uitgangspunten voor de ontplooiing van de professionele staf. Ter beheersing van mogelijke negatieve effecten welke uitgaan van de combinatie controle en advies, dienen voorzieningen te worden getroffen. Dit krijgt extra betekenis indien de dienstverlening bij dezelfde cliënt plaatsvindt. Adviesdiensten mogen het professionele beeld van de accountant niet aantasten, noch een bedreiging vormen voor diens objectiviteit. Gezien het specifieke karakter (publieke functie) van de accountantscontrole, dient het management van de meerdienstenorganisatie hierop de nodige aandacht te richten. In het rapport van de European Contact Group worden hiertoe aanbevelingen gedaan. De maatschappij plaatst soms kanttekeningen bij de activiteiten van de hierbedoelde organisaties. Het is van belang dat laatstgenoemden en beroepsorganisaties aandacht geven aan deze signalen. Gedragscodes binnen het beroep en deze organisaties moeten dit proces in positieve zin beïnvloeden. Op een aantal aspecten zal onder het hoofd waarborgen worden teruggekomen. Voorts is het noodzakelijk dat deze organisaties - voor wat de accountantswerkzaamheden betreft - zich richten op de internationale standaarden. In dit verband worden met name genoemd de standaarden van IASC en IFAC, IAPC. De Europese Commissie denkt ook in deze richting, maar pleit voor een Europese inbreng en maakt zich zorgen omtrent het ontbreken van een wettelijk kader voor deze standaarden.

\section{Producten}

Voor het accountantsberoep zijn belangrijke ontwikkelingen gaande. De discussie omtrent de 
rol van de accountant binnen hel proces van corporate governance is van groot belang. Met name international bezien krijgt de accountant een belangrijke rol toebedeeld. Terecht wordt er van meerdere zijden (waaronder het Koninklijk NIVRA) op gewezen, dat ook in Nederland deze discussie moet worden gë̈tensiveerd. Overigens ligt het primaat bij toezichthouders en management. Belanghebbenden (stakeholders) hebben er bchoefte aan ervan verzekerd te zijn dat de huishouding over een adequaat management control system beschikt. de informatie betrouwbaar is en de relevantie wet- en regelgeving wordt nageleefd. Accountants kunnen adviseren omtrent de opzel van dergelijke systemen en de mededelingen terzake van management attesteren. Mede als gevolg van ontwikkelingen op het gebied van de informatietechnologie ontstaan nieuwe - permanente - informatiestromen. Aan deze informatie en de systemen die de informatie voortbrengen, dient zekerheid te worden toegevoegd. Naast nieuwe vormen van informatieverschaffing kan ook een (review)rol worden toebedeeld aan kwartalal-en halfjaarcijfers. Duidelijk waarneembar is de vraag naar meer betrokkenheid van de accountant bij prospectieve informatie. Het beroep moet zich op dit gebied proactief opstellen. In dit verband wordt ook melding gemaakt van het feit dat management wellicht in de toekomst mededelingen moet doen met betrekking tot going concernaspecten. Deze mededeling moet dan door de accountant bevestigd worden. Binnen IAPCverband wordt tevens nog gesteld, dat assurance services zich kunnen richten op: niet-financiële operationele gegevens, statistische analyses. human resource-aangelegenheden, kwaliteitsstandaarden en pertormance-indicatoren. Het Green Paper vermeldt mogelijke activiteiten voor de accountants op het gebied van het milieu en op het sociale terrein. Zoals blijkt bestaat behoefte bij belanghebbenden ain het toevoegen van zekerheid aan informatie, systemen en processen. Accountants dienen bij dit proces een proactieve rol te spelen. Accountants hebben zich tot nu toe deze rol niet altijd adequaat toegeëigend. De aansprakelijkheidsproblematiek heeft hier wel enigszins aan bijgedragen. De internationale ontwikkelingen op dil gebied - waaronder die in de Verenigde Staten - moeten nauwlettend worden gevolgd. Ook in Nederland vindt de discussie omtrent de aansprakelijkheidsproblematiek thans plaats.

\section{Waarborgen}

Teneinde de rol en de positie van de accountant ook in de toekomst te waarborgen, dienen een aantal voorzieningen getroffen te worden. Deze hebben in belangrijke male betrekking op de onathankelijkheid en de objectiviteit van de accountant. Een belangrijke voorwaarde is dat de invloed van management op de benoeming en de beloning vall de accountant niel te groot is. In dit verband kunnen commissarissen en audit committees een belangrijke rol spelen. Ook andere voorzieningen, zoals benoeming voor een vaste periode en nadere regelingen met betrekking tot de lees, kunnen worden genoemd. De organisatie waarbinnen de accountants opereren staat ook een aantal middelen ten dienste. Verplichte partnerrotatie (bijvoorbeeld na zeven jaar), het systeem van een tweede partner, alsmede verplichte consultatie binnen de organisatie in geval van second opinions en fee-onderhandelingen. Het naleven van de standaarden op het gebied van de accountantscontrole, alsmede de overige kwaliteitsaspecten, dienen te worden wargenomen door onathankelijke reviewteams. Deze teams kunnen in bijzondere gevallen ook aandacht besteden aan de relatie controle- en adviesdiensten en fee-aangelegenheden. Bij dit laatste valı te denken aan sterk afwijkende fees van de voorganger of in proposalsituaties. In geval de reikwijdte van de accountantsverklaring wordt aangepast, zal ook de formulering van de verklaring aanpassing behoeven. Ook hier dient IFAC, IAPC een leidende rol te vervullen.

\section{I T E R A T U U R}

Commissie Corporate Governance, (1996), Corporate Governance in Nederland.

European Commission, (1996), Green Paper, the Role, the Position, and the Liability of the Statutory Auditor within the European Union, EC, Brussel

European Contact Group, (1996), Responding to Market Expectations an action plan to reduce the expectation gap. rapport acht grote internationale accountantskantoren.

Fédération des Experts Comptables Européens, (1996), the Role, Position and Liability of the Statutory Auditor in the European Union, FEE, Brussel.

Gortemaker, J.C.A., (1991), Panta Rhei, Erasmus Universiteit Rotterdam. 